\title{
Perivaterian duodenal diverticulum
}

\author{
R. Subhash • V. A. Iyoob - Bonny Natesh
}

Published online: 4 December 2012

(C) Indian Society of Gastroenterology 2012

A 65-year-old male was admitted with recurrent episodes of postprandial abdominal pain and belching associated with fever, chills, and rigor of 2 years' duration. Physical examination revealed tenderness in the right hypochondrium. He had leukocytosis with mild elevation of alkaline phosphatase and transaminases. Serum amylase and lipase were elevated. Ultrasonogram showed evidence of acute pancreatitis with suspicion of a duodenal diverticulum. Contrast enhanced computed tomogram (CECT) confirmed an extraluminal diverticulum in the medial wall of the second part of the duodenum close to the papilla of Vater (Fig. 1). A sideviewing endoscopy confirmed the findings. Since the patient had recurrent episodes of cholangitis and pancreatitis, he underwent exclusion of the duodenal diverticulum in the form of Roux-en-Y choledochojejunostomy with duodenojejunostomy and has remained well since.

Duodenal diverticula are congenital or acquired. The acquired variety is more common, and in $56 \%$ to $80 \%$ of cases, it arises from the second portion of the duodenum, usually along its medial aspect [1]. Approximately $60 \%$ to $75 \%$ of these diverticula are within $2 \mathrm{~cm}$ of the papilla of Vater and are termed perivaterian or juxta papillary diverticula [1]. Only about $10 \%$ of extraluminal diverticula are symptomatic, and of these, $1 \%$ will need intervention [2].

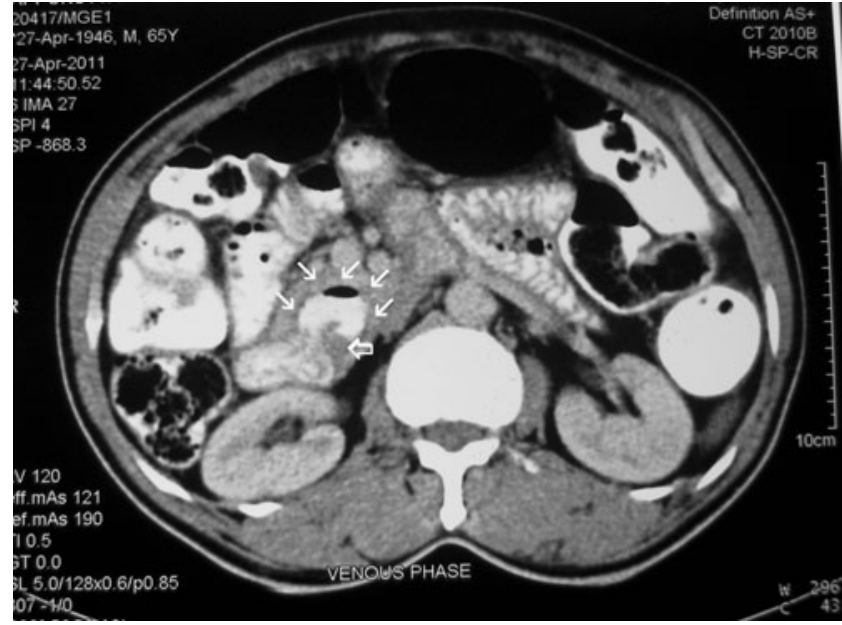

Fig. 1 CECT axial section showing a diverticulum (arrows) in the medial wall of the second part of the duodenum very close to the ampulla of Vater (block arrow) and communicating with the bowel

\section{References}

1. Stoner MC, Arcuni JC, Kellum JM. Small intestinal diverticula. In: Yeo CJ, ed. Shackelford's Surgery of the Alimentary Tract. 6th ed. Philadelphia: Saunders Elsevier; 2007. p. 775-90.

2. Coelho J, Sousa GS, Lobo DN. Laparoscopic treatment of duodenal diverticulum. Surg Laparosc Endosc. 1999;9:74-7.
R. Subhash $(\varangle) \cdot$ V. A. Iyoob $\cdot$ B. Natesh

Department of Surgical Gastroenterology,

Medical College Trivandrum, Trivandrum 695 011, Kerala, India

e-mail: drsubhashr@gmail.com 